\title{
Corte Suprema
}

\section{"Belmar Núñez, Herminda con Servicio de Salud TALCAHUANO Y OTRO" \\ 25 DE ABRIL DE 2005}

\author{
MATERIA: Responsabilidad - órganos de la Administración del Estado \\ - lesión - falta de servicio - nexo de causalidad.
}

\section{LeGISLACIÓN APLICABLE:}

Artículo $6^{\circ}, 7^{\circ}$ y 38 inciso $2^{\circ}$ CPR - artículo $4^{\circ}$ y 42 LOCBGAE - artículo 141 LOCM - artículo 19 inciso $1^{\circ}, 1699$ y 1700 CC.

\section{DOCTRINA:}

La sentencia desestima una demanda de indemnización de perjuicios fundada en la omisión de prestaciones de salud que correspondía suministrarle a la actora, deducida en contra del Servicio de Salud Talcahuano y de la Municipalidad de Penco, por no resultar acreditada la relación causal entre el daño invocado por esta y la actuación que se reprocha. Con ello, sostiene que para que la especie de responsabilidad de que se trata pueda ser reclamada deberá existir y acreditarse en juicio: un vínculo de causalidad entre la falta de servicio - producida por vía de acción u omisión- y el resultado nocivo, en términos de que aquella sea determinante en la generación del evento dañoso.

Santiago, veinticinco de abril de dos mil seis.

\section{Vistos:}

En estos autos rol N $\mathrm{N}^{\circ}$ 5.826-05, correspondientes al rol $\mathrm{N}^{\circ} 790$ 2004 del Segundo Juzgado Civil de Talcahuano, sobre juicio ordinario de indemnización de perjuicios, caratulado: Herminda del Carmen Belmar Núñez con Servicio de Salud Talcahuano y otra, la actora ha deducido recurso de casación en el fondo en contra de la sentencia de la Corte de Apelaciones de Concepción, que revocó la de primer grado, negando lugar a la demanda.

Se trajeron los autos en relación. 


\section{Considerando:}

Primero: Que en el recurso se denuncian como vulnerados por la sentencia en contra de la cual se dirige los artículos $4^{\circ}$ de la Ley $\mathrm{N}^{\mathrm{o}}$ 18.575, Orgánica Constitucional sobre Bases Generales de la Administración del Estado; 141 de la Ley $\mathrm{N}^{\circ}$ 18.695, Orgánica Constitucional de Municipalidades; 19 inciso $1^{\circ}, 1699$ y 1700 del Código Civil;

Segundo: Que, explicando de qué manera se produjo la transgresión de las dos primeras disposiciones legales antes mencionadas, señala la recurrente que ello ocurrió al desestimar el fallo impugnado la demanda deducida por su parte -revocando lo deducido en primera instancia- en razón de no estimar probado que la actividad o inactividad imputada a los organismos estatales demandados haya sido la causa de los daños que se aducen por la parte demandante. Considera la recurrente que semejante conclusión no se aviene con la realidad del proceso, en el cual se recogió prueba testimonial y documental, que permite dar por acreditados los presupuestos de la pretensión contenida en su demanda, esto es: a) que existió falta o disfunción del servicio que la repartición pública demandada estaba obligada a prestar; b) el perjuicio causado a la actora y c) la relación de causalidad entre la falta de servicio y el daño sufrido;

Tercero: Que, en lo atinente a la infracción de los artículos 1699 y 1700 del Código Civil, a los que la recurrente atribuye la calidad de normas reguladoras de la prueba, en cuanto asignan, según afirma, pleno valor probatorio a las declaraciones prestadas por los interesados en un instrumento público; ello habría tenido lugar, al haberse desconocido en la sentencia que se impugna, el mérito de convicción que emana de una hoja de interconsulta proveniente del Consultorio de Penco, de la historia clínica y antecedentes gineco-obstétricos originada en el mismo establecimiento y de una cotización para la extracción del DIU (dispositivo intrauterino), emitida por el Servicio de Salud de Talcahuano; documentos que constituyen instrumentos públicos y que acreditan la relación existente entre la sintomatología y diagnóstico del DIU en la cavidad abdominal de la paciente -actora en el juicio- y los perjuicios cuya indemnización se impetra en la demanda;

Cuarto: Que, a la conclusión, sostiene la recurrente que la transgresión de las disposiciones legales señaladas -incluyendo la del artículo 19 inciso $1^{\circ}$ del Código Civil, al desconocerse el tenor literal de los artículos $4^{\circ}$ de la Ley $\mathrm{N}^{\circ} 18.575$ y 141 de la Ley $\mathrm{N}^{\circ} 18.695$ - influyó sustancialmente en la parte dispositiva de la sentencia recurrida, pues, de no haberse producido los errores jurídicos denunciados, en su interpretación y aplicación, se habría dado por establecida la responsabilidad de las entidades demandadas, por falta de servicio y, confirmándose lo 
resuelto en el fallo de primera instancia, se habría acogido la demanda de indemnización de perjuicios;

Quinto: Que, abordando el análisis de la cuestión propuesta en el recurso, debe tenerse presente que en estos autos Herminda del Carmen Belmar Núñez dedujo demanda de indemnización de perjuicios en contra del Servicio de Salud de Talcahuano y de la Municipalidad de Penco, fundándola en el hecho de que ambos organismos de la Administración del Estado habrían incurrido en omisión respecto de las prestaciones de salud que correspondía suministrársele a la actora; situación que se evidenció al no habérsele retirado un dispositivo intrauterino en su ultimo parto, durante el año 1998, ni con ocasión de una operación de esterilización a que fue sometida días más tarde, en ambos casos, en el Hospital de Lirquén; lo que hizo posible que dicho dispositivo, que le había sido implantado en el Consultorio Municipal de Penco, emigrara hacia el abdomen, provocándole, desde esa fecha, diarreas con sangre, náuseas y agudos trastornos abdominales, con dificultad para deambular, decaimiento y desánimo;

Sexto: Que, habiendo la sentencia de primer grado acogido parcialmente la demanda y, únicamente en contra de la Municipalidad de Penco, en segunda instancia se la revocó, por estimar los jueces que la pronunciaron que, con el mérito de la prueba recogida en el proceso, no resultó acreditada la relación causal entre el daño invocado por la actora y la actuación que se reprocha a la entidad reclamada;

Séptimo: Que, aun cuando en la demanda se cita como único fundamento legal el artículo 38 inciso $2^{\circ}$ de la Constitución Política de la República, es lo cierto que la exposición de motivos contenida en el respectivo libelo evidencia que por su intermedio la actora persigue la responsabilidad civil de órganos de la Administración del Estado, por falta de servicio; pretensión que, dentro de nuestro ordenamiento, se cimenta no solo en la precitada norma fundamental sino también en los artículos 4 y 44 de la Ley $\mathrm{N}^{\circ} 18.575$, Orgánica Constitucional de Bases Generales de la Administración del Estado; disposición esta última que, en lo específico prescribe: "Los órganos de la Administración -entre los cuales, su artículo $1^{\circ}$ inciso 2 incluye a las Municipalidades-serán responsables del daño que causen por falta de servicio";

Octavo: Que la "falta de servicio", constituida así por mandato legal, en "fuente generadora directa de la responsabilidad del Estado", tiene lugar, según lo ha señalado la jurisprudencia, cuando los órganos o agentes estatales no actúan, debiendo hacerlo, o cuando su accionar es tardío o defectuoso, provocando en uno u otro caso, un daño a los usuarios del respectivo servicio público. Obviamente, para que semejante especie de responsabilidad pueda ser reclamada deberá existir $-\mathrm{y}$ acreditarse en juicio, cuando se exigiere por vía jurisdiccional-, un vínculo de causalidad entre la falta de servicio -producida por vía de 
acción u omisión- y el resultado nocivo, en términos de que aquella sea determinante en la generación del evento dañoso;

Noveno: Que, como se apuntó en el basamento sexto de este fallo, los sentenciadores de segunda instancia desestimaron la pretensión de la demandante Herminda Belmar Núñez, por considerar que no se hallaba acreditada con la prueba agregada al expediente la relación de causalidad entre la conducta atribuida a los organismos estatales demandados y los daños cuyo resarcimiento era impetrado por aquella;

Décimo: Que, al fundamentar su recurso de casación, la demandante refutó semejante decisión de la sentencia impugnada, aseverando que la responsabilidad civil, por falta de servicio, de su contraparte había resultado debidamente establecida con el mérito de la prueba testimonial e instrumental rendida en la causa. Un planteamiento de esta índole, según puede observarse, importa controvertir la situación de hecho fijada por los jueces del fondo, ámbito de competencia que les es privativo, quedándole vedado al tribunal de casación revisar los hechos establecidos por aquellos en su sentencia, salvo que, al hacerlo, hubieran desatendido lo dispuesto en leyes reguladoras de la prueba y cuya vulneración hubiera sido denunciada en el recurso. Únicamente en el evento de comprobarse la transgresión de esta especie de normas legales, el tribunal de casación se encontraría habilitado para determinar hechos nuevos en la correspondiente sentencia de reemplazo. No correspondiendo a la categoría mencionada los preceptos que se denuncian como infringidos en el primer capítulo de errores de derecho denunciados en el recurso artículos $4^{\circ}$ de la Ley $\mathrm{N}^{\circ} 18.575$ y 141 de la Ley $\mathrm{N}^{\circ} 18.695$, corresponde que se le desestime, por tal concepto;

Undécimo: Que en lo tocante al segundo grupo de transgresiones normativas a que alude el recurso y que, como se señaló en el basamento tercero de la presente sentencia, incidirían en los artículos 1699 y 1700 del Código Civil, para demostrar la inconsistencia de lo argüido en este aspecto, basta apuntar que la documentación mencionada como instrumento público dista de tener tal carácter, al no avenirse con la definición que de esa clase de documentos se contiene en la primera de las disposiciones legales citadas. Por otra parte, la apreciación del mérito de convicción que emana de esa prueba documental constituye, asimismo, una cuestión de hecho, no susceptible de examinarse por vía de la casación, con la ya señalada excepción de que en la operación intelectual que ello supone se hubieran transgredido leyes reguladoras de la prueba de aquellas que asignan a ciertos medios un determinado valor probatorio;

Duodécimo: Que, acorde con los razonamientos precedentemente desarrollados, por no haberse producido los errores de derecho, invocados como fundamento del recurso de nulidad de fondo, procede que este sea desestimado. 
Y de conformidad, asimismo, con lo dispuesto en los artículos 764 , 767 y 805 del Código de Procedimiento Civil, SE DECLARA que se rechaza el recurso de casación en el fondo deducido en lo principal del escrito de fs. 332 en contra de la sentencia de veintinueve de septiembre del año dos mil cinco, escrita a fs.328. Regístrese y devuélvase, con sus agregados.

Redacción a cargo del Ministro Sr. Oyarzún. Rol No 5.826-05.Pronunciado por la Tercera Sala, integrada por los Ministros Sr. Domingo Yurac, Sr. Milton Juica y Sr. Adalis Oyarzún; y los Abogados Integrantes Sres. José Fernández y Arnaldo Gorziglia. 